\title{
Argentine references for the assessment of body proportions from birth to 17 years of age
}

\author{
Mariana del Pino ${ }^{a}$, M.D., Alicia B. Orden ${ }^{b}$, M.D., María A. Arenas ${ }^{a}$, M.D. and \\ Virginia Fano ${ }^{a}$, M.D.
}

\begin{abstract}
Introduction.Abnormal body proportions may indicate skeletal disorders; therefore, their detection has great clinical significance.

Objectives.To estimate centiles for head circumference/height $(\mathrm{HC} / \mathrm{H})$ and sitting height/height $(\mathrm{SH} / \mathrm{H})$ ratios, and assess their diagnostic usefulness among a group of children with skeletal dysplasia.

Methods.Centiles 3, 10, 25, 50, 75, 90 and 97 for $\mathrm{HC} / \mathrm{H}$ and $\mathrm{SH} / \mathrm{H}$ ratios were estimated with the LMS method using Box-Cox transformation to normalize data distribution for each age. $Q-Q$ plot tests were applied to evaluate normality of residuals and the $Q$ test to calculate goodness-of-fit. Results. The sample included 4818 girls and 4803 boys, all healthy, between 0-17 years old. The median of the $\mathrm{SH} / \mathrm{H}$ ratio for each age decreased from 0.67 at birth to 0.57 at age 4 . At 12 years of age, values reached 0.52 and 0.53 for males and females, respectively, remaining unchanged until age 17. The median of the $\mathrm{HC} / \mathrm{H}$ ratio decreased from 0.45 at 6 years old to 0.34 at 17 years old for both sexes. Z-scores for SH/H among 20 children diagnosed with hypochondroplasia were better at showing abnormal proportions than the $\mathrm{SH} / \mathrm{H}$ ratio not adjusted by age.

Conclusions.Estimated centiles for $\mathrm{HC} / \mathrm{H}$ and $\mathrm{SH} / \mathrm{H}$ ratios show that the most dramatic changes in body proportions occur in the prepubertal period. These references allow an earlier detection of abnormal body proportions in children with skeletal dysplasia.

Key words: sitting height/height ratio, body proportions, head circumference/height ratio, hypochondroplasia, growth curves.
\end{abstract}

http:/ / dx.doi.org/10.5546/ aap.2017.eng.234

To cite: del Pino M, Orden AB, Arenas MA, et al. Argentine references for the assessment of body proportions from birth to 17 years of age. Arch Argent Pediatr 2017;115(3):234-240.

E-mail address:

Mariana del Pino, M.D. mdelpino@intramed.net

Funding:

None.

Conflict of interest: None.

Received: 6-27-2016 Accepted: 12-30-2016 assessment, because they reflect the nutritional and health status during early life. ${ }^{1}$

Abnormal findings in body proportions during the physical examination of a child may suggest the presence of an underlying skeletal disorder. Skeletal dysplasia (SD) is relatively rare, with an incidence of 3.2 out of 10,000 newborn infants in South America. ${ }^{2}$ This condition affects both bones and cartilage. ${ }^{3}$ Clinical signs are variable, but the most characteristic indication is short stature with abnormal body proportion, caused by a large head circumference, or short limbs or trunk in relation to height. In this kind of diseases, the clinical radiological diagnosis can be established in the neonatal period. In other cases, however, long term follow-up sometimes even up to the later stages of growth is required. By this time, clinical and/or radiological signs are evident. ${ }^{3-10}$

Many patients with SD have a HC that is normal for their age (between \pm 2 Z-scores), but clinically "large" for their height. The term relative macrocephaly is used for cases in whom head circumference is normal for a given age and sex, but "high" for their height. Thus, and assuming there is a relationship between these two measurements in the healthy population, references were developed for the head circumference/height $(\mathrm{HC} / \mathrm{H})$ ratio for healthy males and females from birth to 6 years old. ${ }^{11}$ These references are very useful for pediatricians and were collected in the Physical Growth Assessment Guidelines of the Argentine Society of Pediatrics. ${ }^{12}$

The availability of references for the assessment of body proportions is very useful for auxological evaluations. 
Several authors have published sitting height/ height $(\mathrm{SH} / \mathrm{H})$ references, but these correspond to populations with average heights that differ greatly from those in Argentina, due to genetic and/or environmental reasons ${ }^{13-15}$ Therefore, these references are inadequate for the clinical evaluation of body proportions in the Argentinean population.

The objectives of this study were to estimate centiles of $\mathrm{HC} / \mathrm{H}$ and $\mathrm{SH} / \mathrm{H}$ ratios for Argentinean children, and evaluate their diagnostic usefulness to detect abnormal body proportions in children with SD.

\section{POPULATION AND METHODS Population}

$\mathrm{HC} / \mathrm{H}$ and $\mathrm{SH} / \mathrm{H}$ centiles were estimated based on data obtained from the following samples: (a) Longitudinal sample of 250 healthy children, 0-18 years old, measured at Hospital San Roque de La Plata (Buenos Aires) in 1965..$^{16-18}$ From this sample, growth references were estimated for Argentinean boys and girls. These references were used from 1987 until WHO standards were implemented in Argentina. ${ }^{19}$ (b) Cross-sectional sample of 1790 healthy children (878 boys and 912 girls) from La Plata, Buenos Aires, measured in 1970. This population was part of the sample used to establish Argentine references for weight and height in healthy children 4-12 years old. 12,18,20 (c) Cross-sectional sample of 1411 girls and 1442 boys, 2-16 years old, attending state-fund and private schools in La Plata and Gran La Plata, Buenos Aires, from 2007 to 2009. (d) Crosssectional sample of 4556 students of both sexes (2232 girls and 2324 boys), 5-15 years old, attending state-fund and private schools in Santa Rosa-Toay, province of La Pampa, from 2004 to 2007. Based on these data, weight and height centiles were calculated for children and adolescents living in urban areas in the central region of Argentina. ${ }^{21}$

Height, $\mathrm{SH}$ and $\mathrm{HC}$ measurements were standardized in each sample. ${ }^{16-21}$

\section{Data processing and statistical methods}

Dispersion and box plots were developed to remove extreme values. The study included $\mathrm{HC}$, height and $\mathrm{SH}$ data within the range between the mean \pm 5 points from the standard deviation (SD).

Given the time differences among the samples used to estimate centiles, medians of samples between 4-12 years old taken in 1970 and 2007 / 2009 were graphically compared. The T test was applied to compare the different age groups in both samples.
$\mathrm{SH} / \mathrm{H}$ and $\mathrm{HC} / \mathrm{H}$ centiles for each age were estimated by the LMS method. With this method, it is possible to adjust by asymmetry using the Box-Cox (L) transformation, thus normalizing data distribution for each age, ${ }^{22,23}$ considering the median (M) and the distribution variation coefficient (S). Data adjustment allows L, M and S values to change smoothly with the abscissa X (in this case, age). Thus, data can be representative of the population with smooth curves plotted based on the $\mathrm{Y}$ ordinate $(\mathrm{SH} / \mathrm{H}$ and $\mathrm{HC} / \mathrm{H}$ ratios).

For each age, the distribution of $\mathrm{SH} / \mathrm{H}$ and $\mathrm{HC} / \mathrm{H}$ ratios is summarized in three coefficients: $\mathrm{L}, \mathrm{M}$ and $\mathrm{S}$, where L indicates symmetry, $\mathrm{M}$ is the median, and $S$ is the variation coefficient for each age and sex. These parameters were calculated following the maximum penalized likelihood procedure. ${ }^{23,24}$ Centiles were calculated using the formula below: $:^{22,24}$

$$
C_{100 \alpha}(t)=M(t)\left(1+L(t) S(t) Z_{\alpha}\right)^{1 / L(t)}
$$

$\mathrm{Z}_{\alpha}$ is the equivalent normal deviation for the area of tail $\alpha ; \mathrm{C}_{100 \alpha}$ is the $\mathrm{SH} / \mathrm{H}$ or $\mathrm{HC} / \mathrm{H}$ centile corresponding to $\mathrm{Z}_{\alpha^{\prime}}$; is the age in years. $\mathrm{L}(\mathrm{t})$ : asymmetry; $\mathrm{M}(\mathrm{t})$ : median; $\mathrm{S}(\mathrm{t})$ : variation coefficient and $\mathrm{C}_{100 \alpha}(\mathrm{t})$ indicate the corresponding values of each curve at age $t$.

$Q-Q$ plot testswere applied to evaluate normality of residuals and the $Q$ test to calculate goodness-of-fit. ${ }^{24-26}$

The Pearson correlation coefficient was calculated to determine the correlation among $\mathrm{HC}$, height, $\mathrm{SH}$ and length of lower limbs $(\mathrm{LL}=\mathrm{H}-\mathrm{SH})$, transformed into a Z-score (ZS) for 4 age groups ( $\leq 2.99$ years, 3-5.99 years, 6-11.99 years and $\geq 12$ years). ZS was calculated using the formula below:

$$
Z S=\left[(y / M(t))^{L(t)}-1\right] / S(t) * L(t)
$$

Where $y$ is either a measurement $(\mathrm{HC}$, height, etc.) or a ratio $(\mathrm{SH} / \mathrm{H})$ at a certain age, and $\mathrm{L}(\mathrm{t}), \mathrm{M}(\mathrm{t})$ and $\mathrm{S}(\mathrm{t})$ are the smoothed values for that measurement or ratio at the same age. Statistic processing was performed using LMS ChartMaker Pro software.

In a cross-sectional sample of 20 children (10 boys and 10 girls $)<12$ months old, diagnosed with hypochondroplasia based on radiological and clinical criteria ${ }^{13}$, and confirmed by molecular tests, height and $\mathrm{SH}$ values were obtained from their medical records. Anthropometric measurements were taken using standardized 
methods ${ }^{16}$ by the same observer at the Anthropometrics Laboratory of the Service of Growth and Development of Hospital Garrahan. The technical error of measurement was $0.10 \mathrm{~cm}$ in all cases. ${ }^{27,28}$

Height, $\mathrm{SH} / \mathrm{H}$ ratio adjusted by age (current references) and unadjusted $\mathrm{SH} / \mathrm{H}$ ratio data were transformed to ZS. The LMSGrowth ${ }^{29}$ software was used for height and $\mathrm{SH} / \mathrm{H}$ ratio adjusted by age. Unadjusted $\mathrm{SH} / \mathrm{H}$ values were processed manually from median and standard deviation data. ${ }^{12,30}$

\section{RESULTS}

The overall amount of children included, by age group, was $\leq 2.99$ years old: 287 and 282; 3-5.99 years old: 689 and 725; 6-11.99 years old: 2624 and 2585; $\geq 12$ years old: 1203 and 1226, with a total of 4803 boys and 4818 girls.

The graphic comparison and the statistical data obtained in the comparison of samples from 1970 and 2007/2009 indicated that changes in body proportions were not significant (Figures 1. A and $B)$; therefore, both were included in the study.

Table 1 shows the Pearson correlation coefficients for ZS among height, SH, LL and $\mathrm{HC}$ in both sexes and in the 4 age groups. High correlations were obtained between $\mathrm{SH}$ and LL with height, showing values between 0.79 and 0.90 for children $>3$ years old and for both sexes. In children $<3$ years, the correlation coefficients were larger for boys. The correlations between $\mathrm{HC}$ and height fluctuated between 0.30 and 0.50 .

Figures 2. $A$ and $B$ show the $\mathrm{SH} / \mathrm{H}$ ratio references from birth to 17 years of age in the 7 centile format: $3,10,25,50,75,90$ and 97 . Changes in the median for $\mathrm{SH} / \mathrm{H}$ and $\mathrm{HC} / \mathrm{H}$ ratios by age were similar in both sexes. The median of the $\mathrm{SH} / \mathrm{H}$ ratio for each age fell rapidly from about 0.67 at birth to 0.57 at age $3-4$. Then it decreased at a slower pace and, at age 12, the values were at 0.52 for boys and 0.53 for girls. These values remained the same until age 17 .

Figures 3. $A$ and $B$ show the $\mathrm{HC} / \mathrm{H}$ ratio references from 6 to 17 years for girls and boys, respectively, in the 7 centile format: $3,10,25,50$, 75,90 and 97 . The median decreased from values around 0.45 at age 6 to $0.34-0.33$ in both sexes at age 17.

FIGURE 1 (A and B). Comparison of the sitting height/ height ratio median between the 1970 and 2007/2009 samples
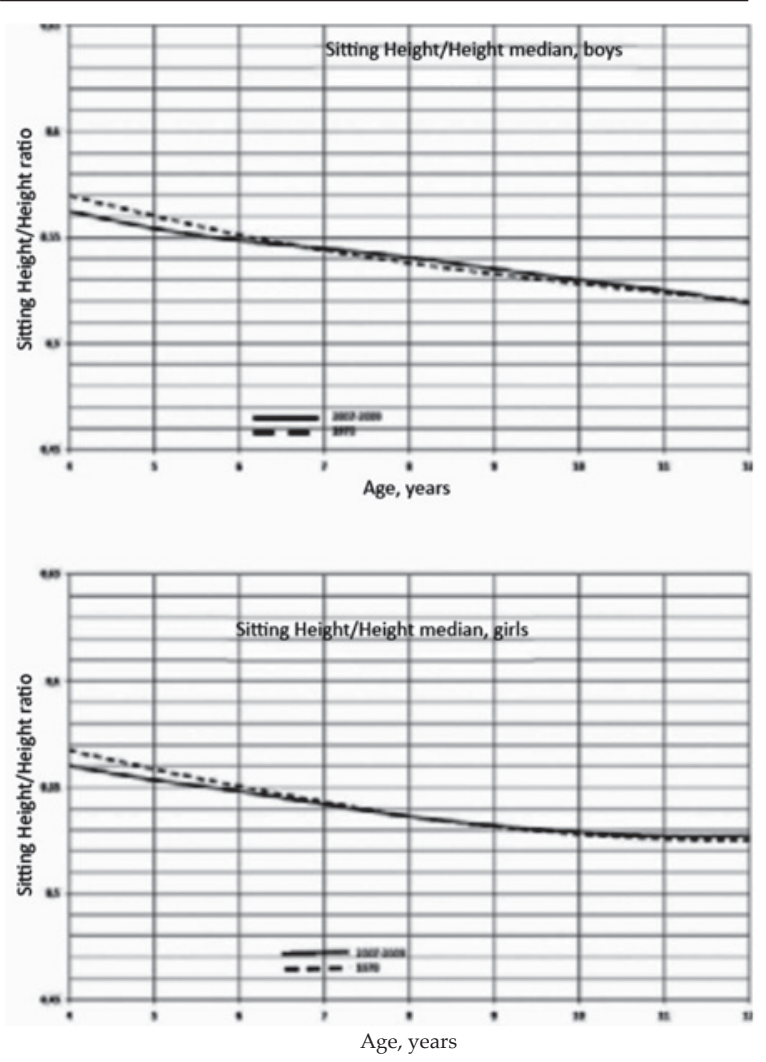

TABLE 1. Correlation coefficients between the Z-score for head circumference, sitting height and lower limb length and height, by age group in both sexes

\begin{tabular}{|c|c|c|c|c|}
\hline Age group & Sex & SH vs. $\mathrm{H}$ & LL vs. H & HC vs. H \\
\hline 0 to 2.99 years old & $\begin{array}{l}\text { Boys } \\
\text { Girls }\end{array}$ & $\begin{array}{l}0.62(\mathrm{~N}=284) \\
0.49(\mathrm{~N}=272)\end{array}$ & $\begin{array}{l}0.52(\mathrm{~N}=284) \\
0.36(\mathrm{~N}=265)\end{array}$ & $\begin{array}{l}0.30(\mathrm{~N}=280) \\
0.31(\mathrm{~N}=272)\end{array}$ \\
\hline 3 to 5.99 years old & $\begin{array}{l}\text { Boys } \\
\text { Girls }\end{array}$ & $\begin{array}{l}0.80(\mathrm{~N}=620) \\
0.83(\mathrm{~N}=661)\end{array}$ & $\begin{array}{l}0.79(\mathrm{~N}=620) \\
0.85(\mathrm{~N}=661)\end{array}$ & $\begin{array}{l}0.44(\mathrm{~N}=417) \\
0.44(\mathrm{~N}=436)\end{array}$ \\
\hline 6 to 11.99 years old & $\begin{array}{l}\text { Boys } \\
\text { Girls }\end{array}$ & $\begin{array}{l}0.82(\mathrm{~N}=2451) \\
0.85(\mathrm{~N}=2387)\end{array}$ & $\begin{array}{l}0.87(\mathrm{~N}=2450) \\
0.90(\mathrm{~N}=2384)\end{array}$ & $\begin{array}{l}0.45(\mathrm{~N}=1761) \\
0.44(\mathrm{~N}=1708)\end{array}$ \\
\hline$\geq 12$ years old & $\begin{array}{l}\text { Boys } \\
\text { Girls }\end{array}$ & $\begin{array}{l}0.83(\mathrm{~N}=1148) \\
0.82(\mathrm{~N}=1143)\end{array}$ & $\begin{array}{l}0.89(\mathrm{~N}=1144) \\
0.87(\mathrm{~N}=1143)\end{array}$ & $\begin{array}{l}0.50(\mathrm{~N}=853) \\
0.40(\mathrm{~N}=865)\end{array}$ \\
\hline
\end{tabular}

H: height; SH: sitting height; LL: lower limbs length; HC: head circumference. 
Table 2 shows the ZS for height, $\mathrm{SH} / \mathrm{H}$ by age and unadjusted $\mathrm{SH} / \mathrm{H}$ for 10 boys and 10 girls $<12$ months old diagnosed with hypochondroplasia. Among these patients, 9/10 girls and $7 / 10$ boys had $\mathrm{SH} / \mathrm{H} \mathrm{Z}$-scores $>2$ for their age, which evidenced an alteration of normal body proportions. In contrast, the ZS for unadjusted $\mathrm{SH} / \mathrm{H}$ ratios did not indicate abnormal values $(>2)$ in any of the children. For example, it should be noted that patient no. 7 showed a high $\mathrm{SH} / \mathrm{H}$ ratio adjusted by age $(\mathrm{ZS}+2.82)$, with no height deficit $(\mathrm{ZS}-1.56)$ and with a normal unadjusted $\mathrm{SH} / \mathrm{H}$ ratio $(\mathrm{ZS}+0.87)$.

\section{DISCUSSION}

This study provides growth references related to the $\mathrm{SH} / \mathrm{H}$ and $\mathrm{HC} / \mathrm{H}$ ratios, by age, for Argentinean boys and girls 0 to 17 years old.
As expected, correlations between the $\mathrm{SH}$ and LL were high for all ages and larger than those published for Dutch children, ${ }^{13}$ between 3 and 12 years old, but similar in both sexes after age 12 .

The $\mathrm{SH} / \mathrm{H}$ ratio decreased from 0.67 at birth to 0.57 at age 4 , and reached values around 0.53 0.52 in adolescents. This shows that the most significant change in body proportions occurs in the first 3 years of life, with more significant growth in the legs than in the trunk, and a mean reduction of $10 \%$ in the $\mathrm{HS} / \mathrm{H}$ ratio. As from age 3 and up to age 12, the decrease in $\mathrm{SH} / \mathrm{H}$ ratio means is lower $(5 \%)$. Beyond that age, there is little change between height and body segments. On the one hand, this reveals the importance of early childhood as a critical period for the detection of postnatal SD. On the other hand, it evidences that adult proportions are established before final adult height is achieved.
FIGURE 2.A. Sitting height/height ratio by age in boys

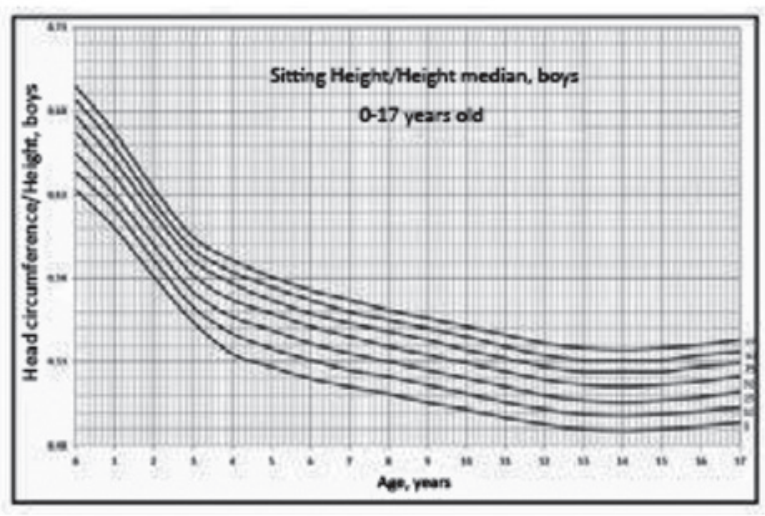

FIGURE 2.B. Sitting height/height ratio by age in girls

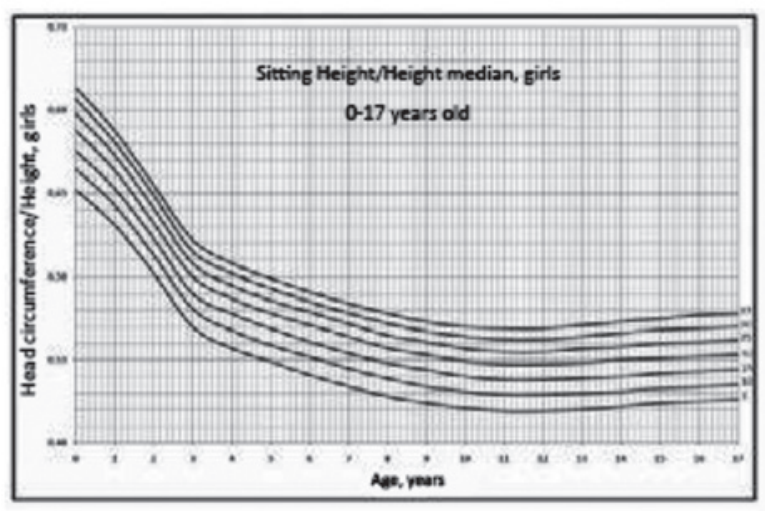

FIgURE 3.A. Head circumference/height ratio by age in boys

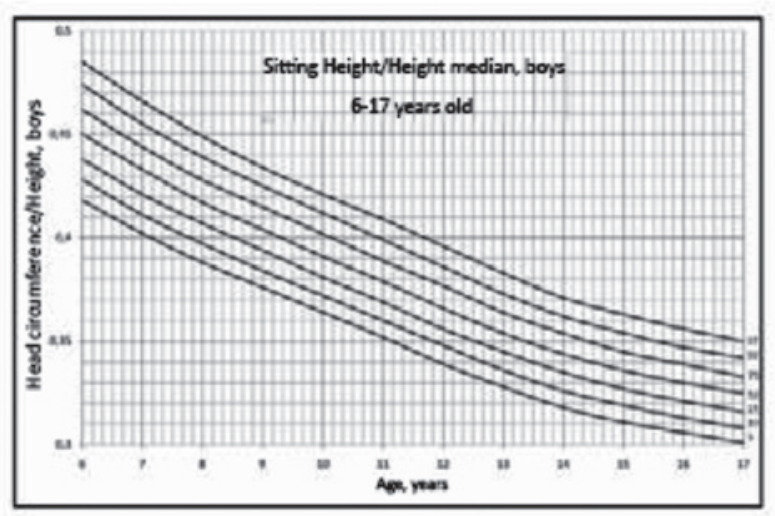

FIGURE 3.B. Head circumference/height ratio by age in girls

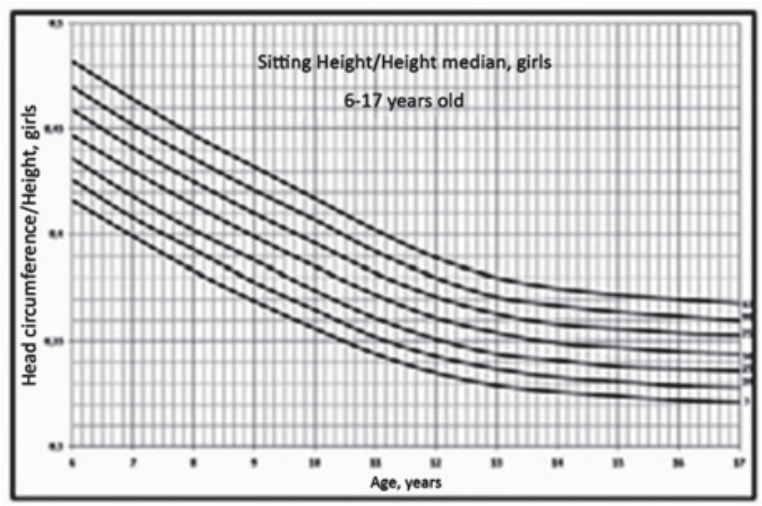


The correlations between the $\mathrm{HC}$ and height have been previously reported for both sexes between the ages of 0 and $6 .{ }^{11,31}$ Such studies show coefficients between 0.30 and 0.79 , similar to those found in this research. Moreover, the existence of correlations between 0.30 and 0.50 between these variables shows the usefulness of relating $\mathrm{HC}$ with height in the clinical practice. The $\mathrm{HC} / \mathrm{H}$ ratio decreases by $9 \%-10 \%$ between the ages of 6 and 17, which shows that the change in body proportions between the $\mathrm{HC}$ and total height occurs, mostly, during childhood, together with a greater development of the brain. . $^{1,30}$

These references were drawn up based on the need to adjust $\mathrm{SH}$ and $\mathrm{HC}$ with the height for each age, so as to make anthropometric diagnosis more accurate when evaluating undiagnosed children with short stature. This is particularly useful in the first years, when there are few radiological and clinical signs, and when other causes of retarded growth have been ruled out. In these cases, the presence SDs, such as hypochondroplasia, should be considered. ${ }^{9}$ When no other family members are affected, this disorder is generally diagnosed after the first years of life, when the clinical abnormality in proportions is more evident.

TABLE 2. Z-scores for height, sitting height/height adjusted by age and unadjusted sitting height/height in 20 children diagnosed with hypochondroplasia

\begin{tabular}{lccccc}
\hline Patient & Age & Sex & Height & SH/H/age & SH/H \\
\hline 1 & 0.26 & M & -2.87 & 1.38 & 0.32 \\
2 & 0.27 & M & -2.39 & 2.05 & 0.71 \\
3 & 0.36 & M & -3.06 & 3.63 & 1.34 \\
4 & 0.36 & M & -2.39 & 3.78 & 1.36 \\
5 & 0.37 & M & -0.66 & 1.85 & 0.72 \\
6 & 0.39 & M & -2.82 & 2.42 & 0.71 \\
7 & 0.62 & M & -1.56 & 2.82 & 0.87 \\
8 & 0.67 & M & -3.52 & 4.03 & 1.40 \\
9 & 0.67 & M & -2.34 & 1.65 & 0.72 \\
10 & 0.64 & M & -4.48 & 4.28 & 0.87 \\
11 & 0.22 & F & -0.66 & 1.96 & 0.33 \\
12 & 0.44 & F & -3.94 & 6.03 & 1.40 \\
13 & 0.46 & F & -2.06 & 4.20 & 1.36 \\
14 & 0.61 & F & -2.95 & 4.06 & 0.87 \\
15 & 0.62 & F & -2.12 & 2.88 & 0.71 \\
16 & 0.65 & F & -2.75 & 2.21 & 0.68 \\
17 & 0.76 & F & -3.35 & 2.39 & 0.67 \\
18 & 0.78 & F & -2.52 & 3.36 & 0.88 \\
19 & 0.86 & F & -2.34 & 3.25 & 0.89 \\
20 & 0.92 & F & -3.30 & 2.79 & 0.70 \\
\hline & & & & &
\end{tabular}

$\mathrm{SH} / \mathrm{H}$ / age: sitting height/ height ratio adjusted by age; $\mathrm{SH} / \mathrm{H}$ : unadjusted sitting height/height ratio;

M: male; F: female.

Age: expressed in decimal fractions for the year of age.
Table 2 shows an example of the usefulness of these references: an alteration of body proportions can be observed, even when the height is normal or only slightly low in 12-months-old children.

Saunders ${ }^{11}$ showed greater sensitivity to detect macrocephaly with $\mathrm{HC} / \mathrm{H}$ references, in comparison with only $\mathrm{HC}$ references by age in children diagnosed with hypochondroplasia.

Thus, these references allow the early detection of skeletal disorders. This would reduce the number of unnecessary screenings and tests that many children have to undergo when trying to find the cause of growth retardation, or for confirmation of a clinical impression or abnormal body proportions with no auxological evidence.

These references are also useful to restrict the number of possible diagnoses during late childhood in patients with short stature without a certain etiology. In this study, abnormal body proportions are a sign used to evaluate children with short stature without a clear cause. ${ }^{10}$

It is necessary to note certain limitations of this study, such as the lower number of data between birth and age 3, which did not allow the proper adjustment of data. Another limitation is that the sample is not representative of all regions in Argentina. The different genetic composition of each region may influence body proportions.

However, the anthropometric data used to establish the references were taken from healthy populations, by trained personnel and following the standards of the Argentine Society of Pediatrics. ${ }^{12}$ In addition, more than 200 values were available for each age group and sex, between the ages of 4 and 15, which makes the sample adequate to establish growth references to assess body proportions between birth and 17 years of age.

To conclude, estimated $\mathrm{HC} / \mathrm{H}$ and $\mathrm{SH} / \mathrm{H}$ centiles show that the more dramatic changes in body proportions occur in the prepubertal period. These references allow the earlier detection of abnormal body proportions, which in turn improves SD diagnosis in children.

\section{Note:}

Values obtained for L, M and S, by age, are available atgarrahan@gov.ar/tdecrecimiento for incorporation to the program LMSGrowth (www. healthforallchildren.co.uk).

\section{Acknowledgments}

To Lola Alcázar and Matías Santos del Pino for setting up the database. 


\section{REFERENCES}

1. Bogin B, Varela-Silva MI. Leg length, body proportion, and health: a review with a note on beauty. Int J Environ Res Public Health 2010;7(3):1047-75.

2. Barbosa-Buck CO, Orioli IM, Da Graça Dutra M, LópezCameloJ, et al. Clinical epidemiology of skeletal dysplasia's in South America. Am J Med Genet A 2012;158A(5):1038-45.

3. Bonafe L, Cormier-Daire V, Hall C, Lachman R, et al. Nosology and classification of genetic skeletal disorders: 2015 revision. Am J Med Genet A 2015;167A(12): 2869-92.

4. Krakow D.Skeletal dysplasias. Clin Perinatol 2015;42(2):30119.

5. Guzmán-Huerta ME, Morales AS, Benavides-Serralde A, Camargo-Marín L, et al. Prenatal prevalence of skeletal dysplasias and a proposal ultrasonographic diagnosis approach. Rev Invest Clin 2012;64(5):429-36.

6. Binder G, Renz A, Martinez A, Keselman A, et al. SHOX haploinsufficiency and Leri-Weill dyschondrosteosis: prevalence and growth failure in relation to mutation, sex, and degree of wrist deformity. J Clin Endocrinol Metab 2004;89(9):4403-8.

7. Binder G, Ranke MB, Martin DD. Auxology is a valuable instrument for the clinical diagnosis of SHOX haploinsufficiency in school-age children with unexplained short stature. J Clin Endocrinol Metab 2003;88(10):4891-6.

8. Rappold G, Blum WF, Shavrikova EP, Crowe BJ, et al. Genotypes and phenotypes in children with short stature: clinical indicators of SHOX haploinsufficiency. JMed Genet 2007;44(5):306-13.

9. Fano V, Gravina LP, Pino MD, Chertkoff L, et al. High specificity of head circumference to recognize N540K mutation in hypochondroplasia. Ann Hum Biol 2005;32(6):782-8.

10. Malaquias AC, Scalco RC, Fontenele EG, Costalonga EF, et al. The sitting height/height ratio for age in healthy and short individuals and its potential role in selecting short children for SHOX analysis. Horm Res Paediatr 2013;80(6):449-56.

11. Saunders CL, Lejarraga H, Del Pino M. Assessment of head size adjusted for height: an anthropometric tool for clinical use base on Argentinian data. Ann Hum Biol 2006; 33(4):415-23.

12. Sociedad Argentina de Pediatría. Comité Nacional de Crecimiento y Desarrollo. Guía para la evaluación del crecimiento físico. 3.a ed. Buenos Aires: Sociedad Argentina de Pediatría; 2013.

13. Fredriks AM, Van Buuren S, Van Heel WJ, DijkmanNeerincx RH, et al. Nationwide age references for sitting height, leg length, and sitting height/ height ratio, and their diagnostic value for disproportionate growth disorders. Arch Dis Child 2005;90(8):807-12.

14. Lee TS, Chao T, Tang RB, Hsieh CC, et al. A longitudinal study of growth patterns in schoolchildren in one Taipei District. II: Sitting height, arm span, body mass index and skinfold thickness. J Chin Med Assoc 2005;68(1):16-20.
15. Bundak R, Bas F, Furman A, Günöz H, et al. Sitting height and sitting height/ height ratio references for Turkish children. Eur J Pediatr 2014;173(7):861-9.

16. Cusminsky M, Castro E, Acciona L Ch, Jubany E, et al. Estudio longitudinal de crecimiento y desarrollo del niño en La Plata. Comisión de Investigaciones Científicas de la Provincia de Buenos Aires 1966;1-3 Pc:3-13.

17. CusminskyM,LozanoGA,CastroEP,FellerJ, etal. Crecimiento y desarrollo del niño normal de 4 a 12 años. Estudio transversal, La Plata, Argentina. At Sociedad Argentina de Pediatría. XIV Congreso Internacional de Pediatría; del 3 al 9 de octubre de 1974; Buenos Aires, Argentina; 5:52-61.

18. Lejarraga H, Orfila G. Estándares de peso y estatura para niñas y niños argentinos desde el nacimiento hasta la madurez. Arch Argent Pediatr1987;85(4):209-22.

19. Abeyá Gilardon E, Anigstein C, Bay L, Caíno S, et al. Referencias y estándares de crecimiento en la Argentina. Consideraciones del Grupo ad hoc para el análisis de las tablas de la Organización Mundial de la Salud y su uso en la Argentina. Arch Argent Pediatr2007;105(2):159-66.

20. Lejarraga H, del Pino M, Fano V, Caino S, et al. Referencias de peso y estatura desde el nacimiento hasta la madurez para niñas y niños argentinos. Incorporación de datos de la OMS de 0 a 2 años, recálculo de percentilos para obtención de valores LMS. Arch Argent Pediatr2009;107(2):126-33.

21. Orden AB, Apezteguía MC. Weight and height centiles of Argentinian children and adolescents: a comparison with $\mathrm{WHO}$ and national growth references. Ann Hum Biol2016;43(1):9-17.

22. Cole TJ. Fitting smoothed centile curves to reference data. J R Stat Soc Ser A Stat Soc 1988;151(3):385-418.

23. Cole TJ, Green PJ. Smoothing reference centile curves: the LMS method and penalized likelihood. Stat Med 1992;11(10):1305-19.

24. Van Buuren S, Fredriks M. Worm plot: a simple diagnostic device for modeling growth references curves. Stat Med 2001;20(8):1259-77.

25. Royston P, Wright EM. Goodness-of-fit statistics for agespecific reference intervals. Stat Med 2000;19(21):2943-62.

26. Pan H, Cole TJ. A comparison of goodness of fit tests for age-related reference ranges. Stat Med 2004;23(11):1749-65.

27. Caíno S, Adamo P, Kelmansky D, Lejarraga H. Impacto del entrenamiento sobre el error de mediciones antropométricas. Arch Argent Pediatr2002;100(2):110-3.

28. Caíno S, Kelmansky D, Adamo P, Lejarraga H. Shortterm growth in head circumference and its relationship with supine length in healthy infants. Ann Hum Biol 2010;37(1):108-16.

29. LMS growth program. [Accessed on: January 04, 2017.] Availableat:http:/ / www.healthforallchildren.com/shopbase/shop/software/lmsgrowth.

30. Falkner F, Tanner JM, eds. Human Growth. A Comprehensive Treatise. 2nd ed. New York:Springer; 1986

31. Illingworth RS, Eid EE. The head circumference in infants and other measurements to which it may be related. Acta Paediatr Scand 1971;60(3):333-7 